\title{
A Compilation of Dilution Graph Data for Open Stope Hangingwall Design
}

\author{
G. Capes University of Saskatchewan, Canada; Newcrest Mining Ltd, Australia \\ D. Milne University of Saskatchewan, Canada
}

\begin{abstract}
This paper presents data from a thesis currently being completed on the stability of open stope hangingwalls based on knowledge gained from site visits and data collection at underground mines in Canada, Australia and Kazakhstan. One of the key objectives of the thesis was to add data to the Dilution Graph (Clark, 1998), an empirical design method, which was developed to quantify open stope footwall and hangingwall overbreak prediction. Data collected from the mines, specifically directed at areas of the Dilution Graph which have limited data, and data from literature are presented together to provide a large database of empirical data for hangingwall stability in open stope operations. A discussion is presented on the benefits and pitfalls of the design method and the applied use of the graph with consideration to mine specific design factors.
\end{abstract}

\section{Introduction}

Open stope mining is a bulk mining method used worldwide in a variety of orebody geometries. The stability of the open stope walls and surrounding rock mass in conjunction with metal prices, local mine regulations and the operating costs will influence mine design. In particular, unplanned open stope hangingwall (HW) overbreak, which may be a key contributor to diluting the produced ore, is a significant cost for many open stope mining operations. Over the past 27 years, there have been both qualitative and quantitative empirical methods developed to assess the stability of the stope walls. The methods referenced in this paper include the qualitative modified stability graph method (Potvin, 1988) and the quantitative dilution graph method (Clark, 1998). From this point forward MSG refers to the modified stability graph and DG refers to the dilution graph. Each method provides a relationship between the open stope geometry, rock mass conditions, and stope wall stability based on empirical data. Factors which are external to the input parameters of the methods have been seen to potentially influence stability at various mine sites. These factors may include faulting, stress, undercutting, blasting and other mine specific factors. The effect of these factors is not explicitly accounted for in the empirical methods and a widely used, industry design criteria for these factors does not exist. Databases discussed in this paper have attempted site specific corrections for some of these factors and are recommended for referral. The final database of $405 \mathrm{HW}$ case histories presented here represents a wide range of the external factors and different mining conditions.

\section{Background - the DG method for open stope design}

The DG method (Clark, 1998), one of many of the empirical design methods developed through the University of British Columbia, Canada was created to provide a quantitative approach to stope HW design. The method is based on the format and parameters defined by the qualitative MSG method (Potvin, 1988) which was an update of the original stability graph method (Mathews et al., 1981). In the qualitative methods, stability was assessed as either being stable, potentially unstable, or caved (major HW failure). The DG is based on the ELOS parameter (Clark and Pakalnis, 1997). ELOS (equivalent linear overbreak/ slough) is the volume of the rock failed from the stope HW divided by the HW area. The ELOS value represents an average depth of failure over the HW surface. The definition was developed to eliminate the confusion arising from the various definitions of dilution in use in the industry. Stope profile information used to calculate ELOS is based on data acquired using the cavity monitoring system (Miller et al., 1992). The DG was developed by plotting ELOS values in the MSG format and then using statistics (logistic regression and neural networks) and engineering judgement to create the quantitative design lines. The method has been 
seen in use at many open stope mining operations. Logistic regression has also been used by Mawdesley and Trueman (2003) to examine the placement of stability zones and probability of correct prediction in a similar qualitative empirical method.

The DG is made up of data from 41 stope footwall (FW) and 47 HW case histories. The FW data was removed for the purpose of this thesis, creating a foundation of HW cases on which to perform further research. In order to determine a direction to take for data collection, the MSG and DG lines and previously collected HW data points are shown in Figure 1. The plot demonstrates areas with sparse ELOS data and the truncation of ELOS design lines due to lack of data. One of the objectives of the thesis was to collect data in the zone of interest shown in Figure 1 and update the DG design lines to be representative of the new data.

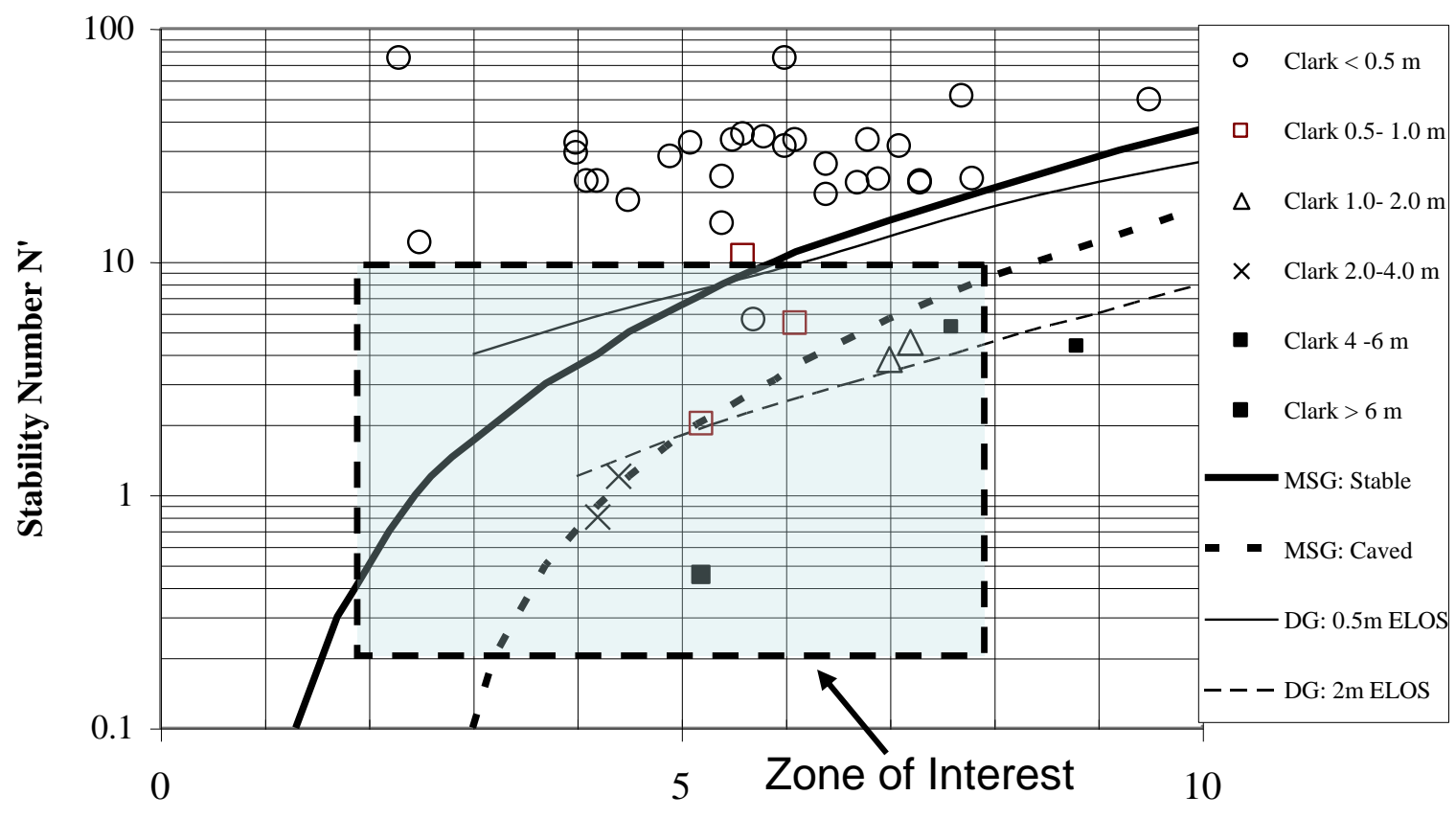

Hydraulic Radius (m)

Figure 1 Approximate position of MSG transition zone (after Potvin, 1988) and DG exterior lines (after Clark, 1998), with Clark (1998) HW data

Since it takes months to years to complete the mining cycle of a stope, significant time was spent on site, from 2003-2007, to gather the required information for the design method input parameters and resultant stope profiles to calculate the ELOS values. The stope shape is represented by the hydraulic radius (HR), defined as the area/perimeter of the stope wall. The rock mass conditions are implicitly represented by the modified stability number (N') as per Potvin (1988) and Clark (1998):

$$
\mathrm{N}^{\prime}=\mathrm{Q}^{\prime} \times \mathrm{A} \times \mathrm{B} \times \mathrm{C}
$$

Q' = modified from the NGI (Q) rock quality index (Barton et al.,1974) with the stress reduction and joint water reduction factors set to one (Potvin, 1988).

A is the stress factor and accounts for the influence of compressive stresses driving instability. The A-factor was modified by Potvin (1988) from a rule of thumb by Mathews et al. (1981) to attempt to account for the effect of stress on opening stability in open stope empirical design. The A-factor is a relationship between intact rock compressive strength and induced stress (elastic behaviour) in the HW to account for any compressive failure. The value of the A factor is 1.0 when the stresses induced in the HW are less than onetenth of the intact rock strength. Computer modelling studies have shown that stresses induced parallel to the largest surface of an excavation are low or negative. Induced HW stresses are also low or negative when the maximum in situ virgin stress is perpendicular to the HW (Clark, 1998; Wang et al., 2006). Clark (1998) suggested that more research is needed to fully understand the effects of stress on stope HW stability and that there is little precedence for using A values less than 1.0 for HWs and FWs as only one of the $106 \mathrm{HW}$ and FW data points from the Potvin (1988) database had an A value other than 1.0. Modelling studies suggest 
that high compressive stresses leading to an A value of less than 1.0 would only tend to occur for stopes with a small hanging wall extent relative to the other stope surfaces in a stress environment where the maximum in situ stress was orientated parallel to the HW. Neither of these circumstances was common in the study. Pakalnis and Vongpaisal (1998) also emphasised the point and suggested that to apply an A value other than 1.0, numerical modelling which shows a HW with a high state of induced stress compared to rock compressive strength must be augmented with observation of the failure mechanism. Also, an extensive literature review did not reveal any evidence showing that a quantitative analysis has been completed which compares the effect of $\mathrm{A}=1$ versus $\mathrm{A}<1$ on stope stability prediction. Thus, the authors have assumed $\mathrm{A}=1$ for the study.

$\mathrm{B}$ is the rock defect factor representing the effect of joint orientation on stability. This value is typically assigned a value of 0.3 due to parallel jointing.

$\mathrm{C}$ is the stope orientation factor representing the effect of the dip is defined as $\mathrm{C}=8-(6 \mathrm{x} \cos \varphi(\mathrm{HW}$ dip$))$ accounting for the fact that vertical walls are inherently more stable than horizontal backs.

\section{Recent data collection}

From 2003-2007, experience was gained in the application of the described empirical methods through discussions at industry short courses, site visits, consultants' visits, employment and data collection at underground mines in Canada, Australia and Kazakhstan. The HW cases from the Clark (1998) database from mines in the Canadian Shield were used as a design starting point. Further data collection was focussed at mines whose rock mass and mining conditions were in or near the zone of interest shown in Figure 1. A short description of the data collection sites is presented below. Other sites visited where substantial stope stability knowledge was accessed include the former Inco Thompson operation in north-central Canada; BHP Cannington mine, Xstrata Zinc lead mine, and Xstrata Copper Enterprise mine, in Queensland, Australia; and the Kazzinc Maleevskiy mine in north-eastern Kazakhstan.

Two months during 2003 were spent on site at the former Hudson Bay Mining and Smelting Ltd (HBMS) Callinan mine in Flin Flon, Canada for the collection of 27 cases in a good quality rock mass with shallow dipping HWs. Subsequent trips were made to a variable quality rock mass at the Cameco Rabbit Lake mine in northern Saskatchewan, Canada. The site provided an opportunity to improve the Sutton (1998) database (11 cases) which Forster et al. (2007) have since been expanding. Three years (2003-2006) were spent on site at the Xstrata Zinc George Fisher mine in Mount Isa, Australia for the collection of 133 cases from a variable quality rock mass with shallow to steep dipping HWs discussed in Capes et al. $(2005 ; 2007)$.

Recent North American literature provides additional data near or within the zone of interest. A weak rock mass database consisting of openings mainly with vertical walls in Nevada, USA from Brady et al. (2005) provided 47 additional relevant cases. A large database of 150 ELOS cases from mines near the Flin Flon, Canada area by Wang (2004) is also presented here for discussion.

All of the databases are described independently such that any mine may select the dataset most representative of their rock mass and mining situation to add to their own database if desired. Information on the technicalities of the individual mining methods, stress conditions, etc. is not provided here but can be found in the referenced literature. All the cases compiled except 10 had HR $<10$. Thus, for clarity, the scale of databases shown will be based on $\mathrm{HR}<10$.

\subsection{Original DG database from Clark (1998): 47 cases}

The Clark (1998) database consists of data from six Canadian mines including Lupin, Westmin, Trout Lake, Detour Lake, Contact Lake, and Ruttan. Thirty of the stopes were considered primary stopes and 17 were mined adjacent to backfill. Other than the Trout Lake data which had stope walls dipping on average of $55^{\circ}$, cases were predominantly dipping $60-90^{\circ}$ with $\mathrm{N}^{\prime}>10$. Additionally, the majority of the $\mathrm{HW}$ cases collected had ELOS $<2 \mathrm{~m}$ (Figure 1). Data shown in the figure represents only the 39 cases with an HR $<10$ to represent data closest to the zone of interest for the study. 


\subsection{Callinan, Rabbit Lake and George Fisher databases from Capes et al. (2005) and (2007): 171 cases}

The many site visits conducted from 2003-2007 provided extensive stope stability knowledge. However, the databases presented below represent sites where the authors were able to spend sufficient time on site to experience the full mining cycle from stope HW prediction to recording actual performance. Each database provides valuable data in or near the zone of interest as well as insight into potential errors in the empirical method which led to the development of other techniques to assess stability of the stope HW in conjunction with the existing approaches.

\subsubsection{Callinan orebodies: 27 cases}

The Callinan mine is one of many mines near Flin Flon, Manitoba, Canada. The orebody is a typical volcanogenic massive sulphide-type copper-zinc deposit (Syme and Bailes, 1993). The predominant mining method is longhole open stoping by longitudinal retreat with a combination of paste filled stopes and pillars with backfill. The HW rock quality Q' values ranged between 2 and 6 . Typical modified stability numbers (N') of 3-7 were calculated due to the low value of the $\mathrm{C}$ factor based on the shallow dipping HW (23-54'). HR ranged from 3.7-7.5 m (strike lengths of 15-40 m) over the small sublevel height of $15 \mathrm{~m}$ with the mining occurring at depths of 1040-1100 $\mathrm{m}$. The database is displayed in Figure 2.

The values of the Callinan parameters were ideal for the zone of the DG which previously lacked data. Some general observations were made that primary stope HW behaviour was similar to secondary stope HW behaviour, undercutting may lead to more overbreak than predicted, and skins of ore not recovered inside the HW could enhance HW stability and create erroneous prediction.

\subsubsection{Rabbit Lake database: 11 cases}

The Rabbit Lake mine is located on the eastern edge of the Athabasca Basin, close to Wollaston Lake, $800 \mathrm{~km}$ north of Saskatoon, Canada. The uranium mineralisation is structurally controlled, and occurs within the basal unit of the Aphebian metasediments (Dishaw, 2005). Sutton (1998) collected input data for the DG from 11 stope HWs of variable rock quality. During this time, the Rabbit Lake mine was producing in an ore zone with a width up to $15 \mathrm{~m}$ dipping between $45-60^{\circ}$ mined using longhole open stoping with delayed backfill. HR ranged from 4.0-8.5 m over a sublevel height of $30 \mathrm{~m}$ with the mining occurring at depths of between approximately 170-260 m below surface. The local rock mass classification based on a combination of unconfined compressive strength and joint wall alteration was correlated to Q' ranging between 0.4-11. Modifications were made to the original ELOS data since it was based on the simple assumption of a triangular wedge based failure shape using the centre ring as a maximum depth of failure and no failure at the limits of the HW strike length. The database is displayed in Figure 3.

One of the key findings of the study was that the hanging wall may fail through various zones of altered HW rock to a higher quality rock, which demonstrated the error associated with the requirement of averaging the HW rock mass quality as a single input into the empirical design methods. Forster et al. (2007) discuss a similar failure profile where the HW sloughs through a lower RQD to a higher RQD geological contact.

\subsubsection{George Fisher orebodies: 133 cases}

The George Fisher lead, zinc, and silver ore deposits lie $22 \mathrm{~km}$ north of Mount Isa, Queensland, Australia. The George Fisher deposit consists of a sequence of stratiform, Middle Proterozoic, Ag-Pb-Zn orebodies that occur entirely within the Urquhart Shale unit of the Mount Isa Group, and is located within the Western Fold Belt of the Mount Isa Inlier (Grenfell and Haydon, 2006), an area which has an extensive deformation history. The predominant mining method in D-Orebody, which has thicknesses ranging between $10-40 \mathrm{~m}$, is transverse open stope mining using delayed backfill. The database is composed of 125 cases from D-orebody and eight cases from the more competent $\mathrm{C}$-orebody which can be divided into 75 primary and 58 secondary stopes. The rock quality Q' values ranged from $0.1-7.2$ with N' of $0.2-13.9$. Stope HW dips varied between $36-90^{\circ}$. The stopes were mined at depths of 600-800 $\mathrm{m}$ with HR ranging between $3.0-7.9 \mathrm{~m}$ (strike lengths of 7-25 m) over one or two sublevel heights of $30 \mathrm{~m}$. The database is displayed in Figure 4.

The key finding of the study was that the averaging approach for estimating rock mass properties for design methods does not always provide the best answer based on available information. This created the need to 
develop supplementary stope HW stability prediction tools. Other key points were that generalising all stope designs into one category can lead to poor design, individual fault characteristics play a role in stope stability, and there was no major difference in average HW depth of failure between primary and secondary stopes. However, mining out of sequence, triple lift pendants and poor cement fill quality or lack of tight fill and/or delayed fill in primary stopes may lead to greater HW failure than predicted and create subsequent stope back failure.

\subsection{Nevada weak rock database from Brady et al. (2005): 47 cases}

This database consists of data from five mines in Nevada composed of weak rock masses. Weak rock masses were defined as having a rock mass rating (RMR) (Bienawski, 1976) of less than $45 \%$ and/or a rock mass quality rating (Q) under 1.0 (Brady et al., 2005). The data was plotted alongside the original Clark (1998) lines and the following comments from the paper suggest a need to adjust the lines at the lower left end of the graph:

"An initial observation ... is that the classical design curves $(E L O S) \ldots$ are inaccurate at low $N$ ' and hydraulic radius values. If hydraulic radius is kept below $3.5 \mathrm{~m}$ in a weak rock mass, the ELOS value should remain under $1 \mathrm{~m}$. It appears a hydraulic radius under $3 \mathrm{~m}$ would not result in ELOS values much greater than $1 \mathrm{~m}$. This result is being further evaluated."

To comply with the other database presented in this paper, the cases described in the database as ELOS $>2 \mathrm{~m}$ category were placed in the ELOS $=2-4 \mathrm{~m}$. The database is displayed in Figure 5.

\subsection{Wang (2004) 148 cases}

The Wang (2004) database consists of 150 (148 with HR<10) HW case histories which include 45 cases from Callinan mine, eight cases from Ruttan mine, and 97 cases from Trout Lake mine. The following brief description of the mining conditions is taken from Wang (2004). The Trout Lake and Callinan deposits comprise a number of stacked or en-echelon concordant massive sulphide lenses underlain by stringer sulphides. The ore zones in both mines vary from two to over $20 \mathrm{~m}$ in thickness. The Trout Lake orebody is generally steeper dipping $\left(65-70^{\circ}\right)$ than the Callinan deposit $\left(40-55^{\circ}\right)$. The Ruttan mine orebody strikes $\mathrm{N} 70^{\circ} \mathrm{E}$, dips $70^{\circ} \mathrm{SE}$ and plunges $70^{\circ}$ to the east. Most of the cases had N'>10, which is outside the zone of interest for the study. However, the data is included for discussion purposes and displayed in Figure 6.

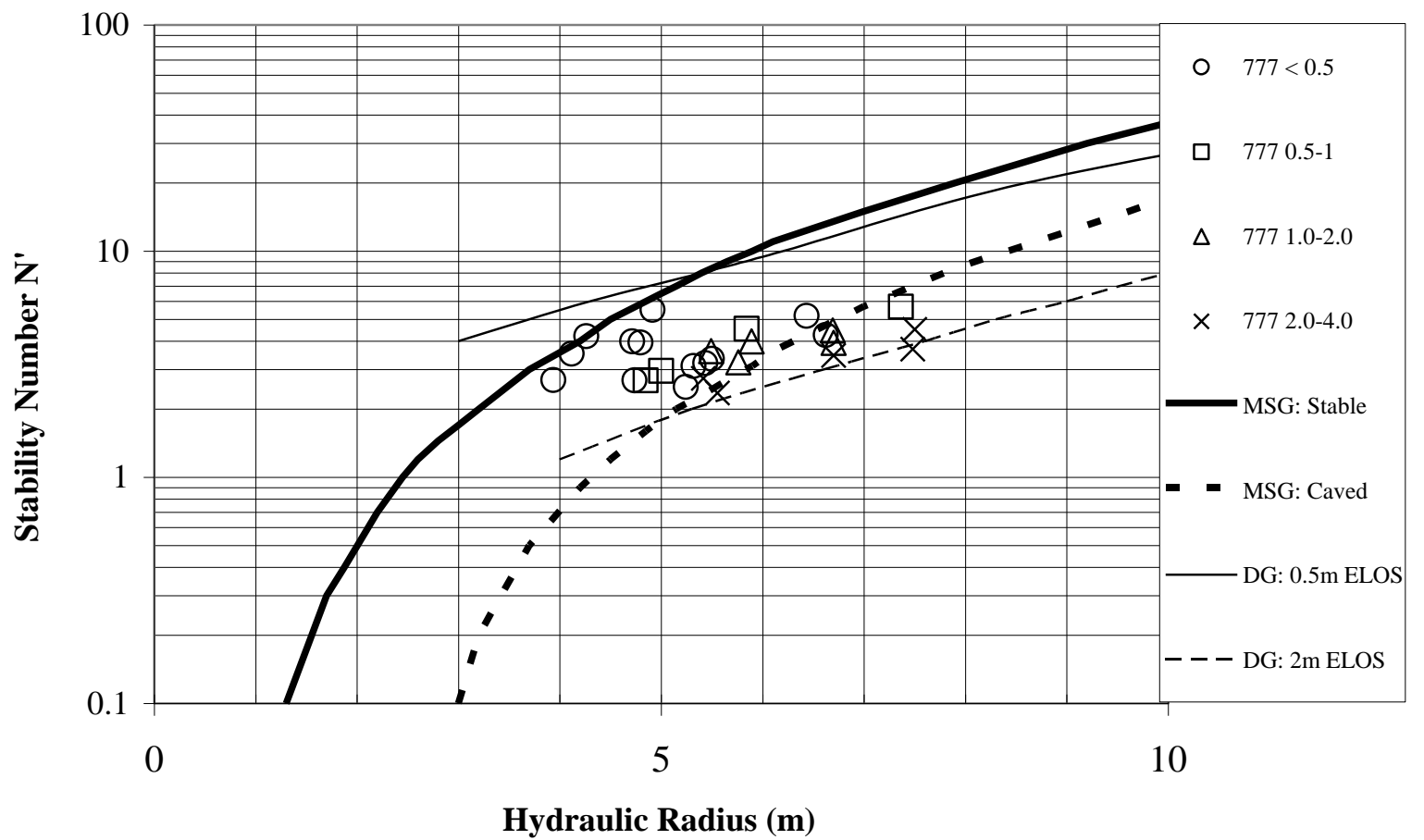

Figure 2 Callinan (777 mine) data from the DG database in Capes et al. (2005): 27 cases 


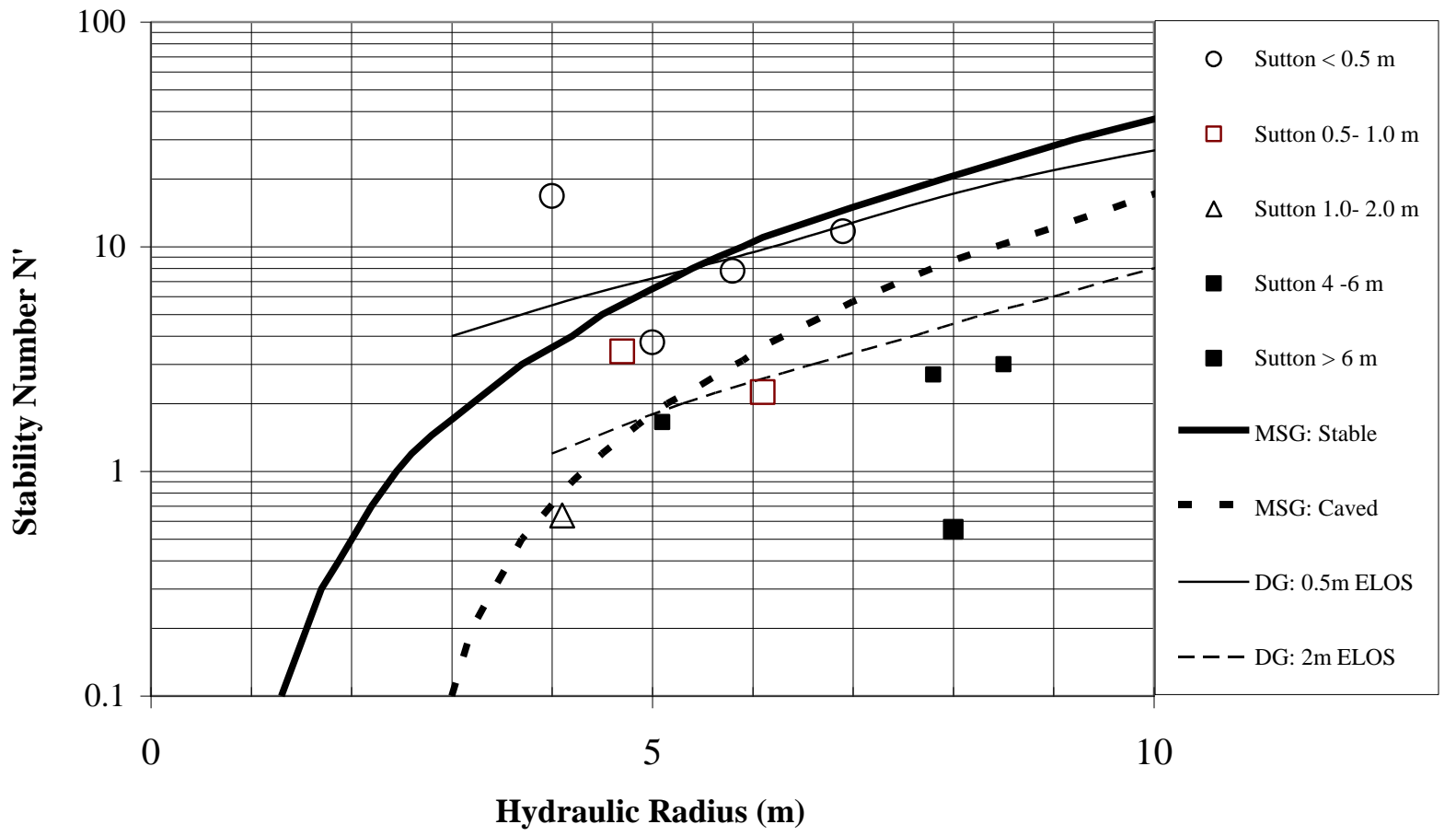

Figure 3 Data modified from Sutton (1998) Rabbit Lake data: 11 cases

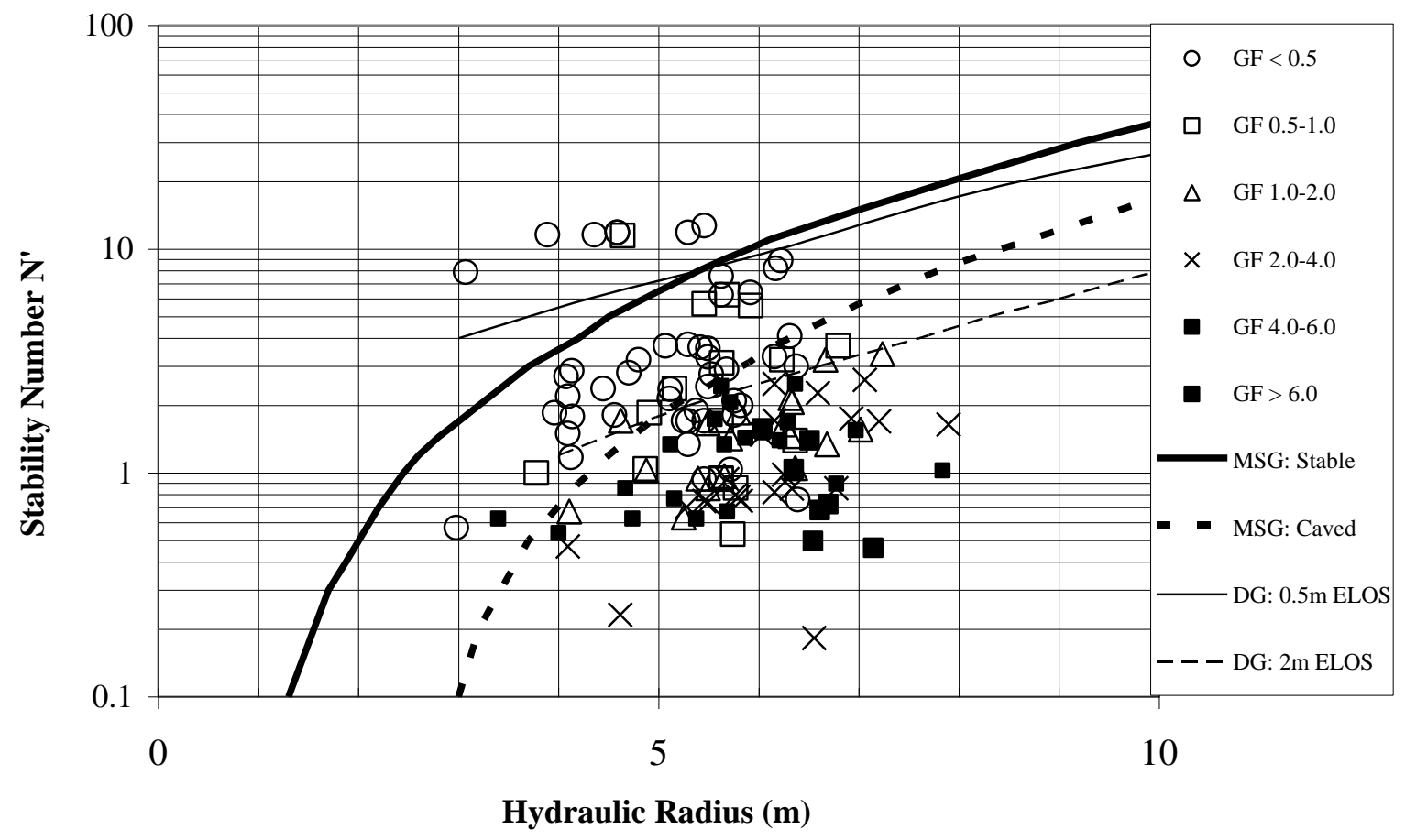

Figure 4 George Fisher (GF) mine data from Capes et al. (2005; 2007): 133 cases 


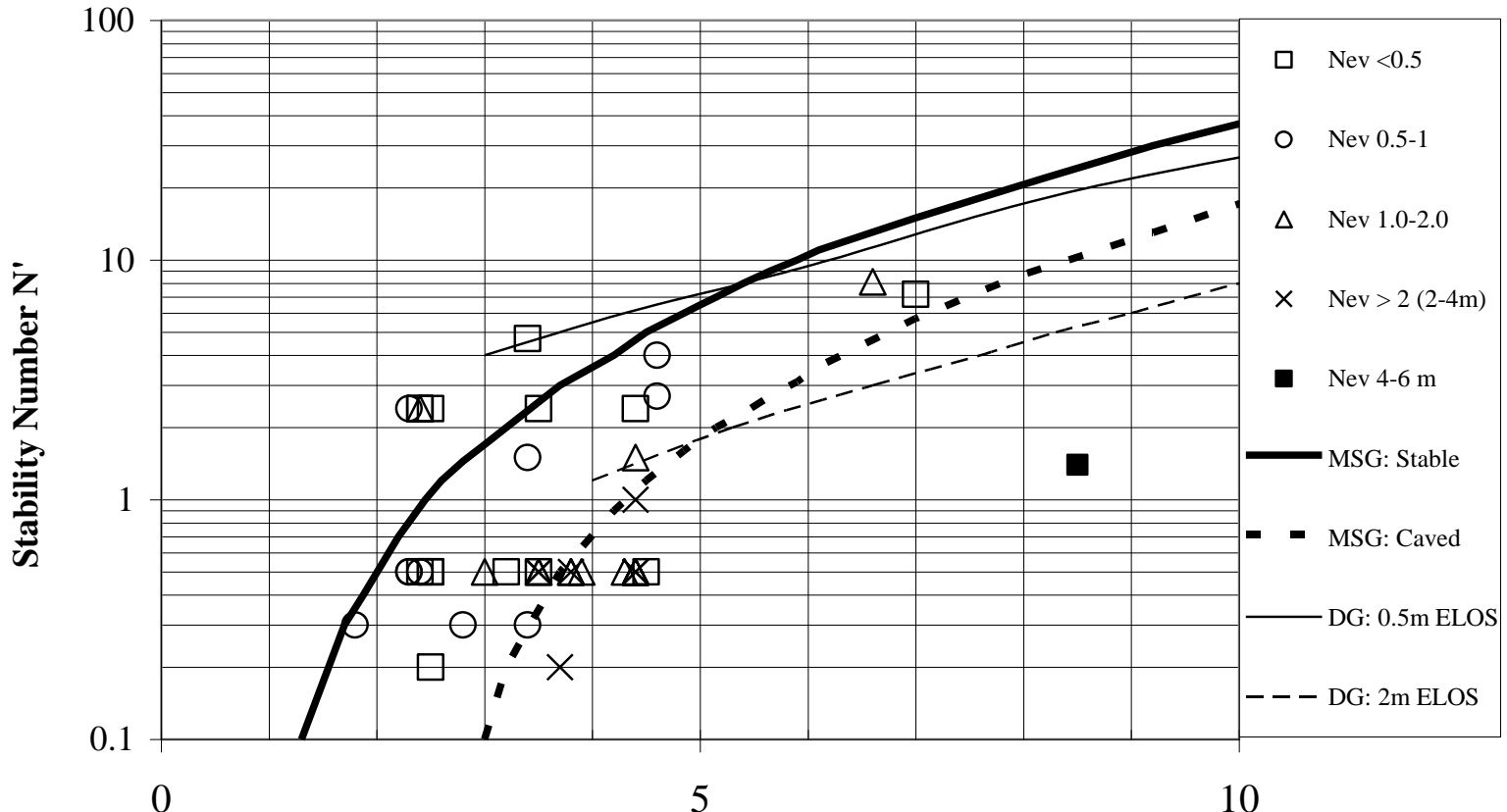

Hydraulic Radius (m)

Figure 5 Nevada weak rock mass data from Brady et al. (2005): 47 cases

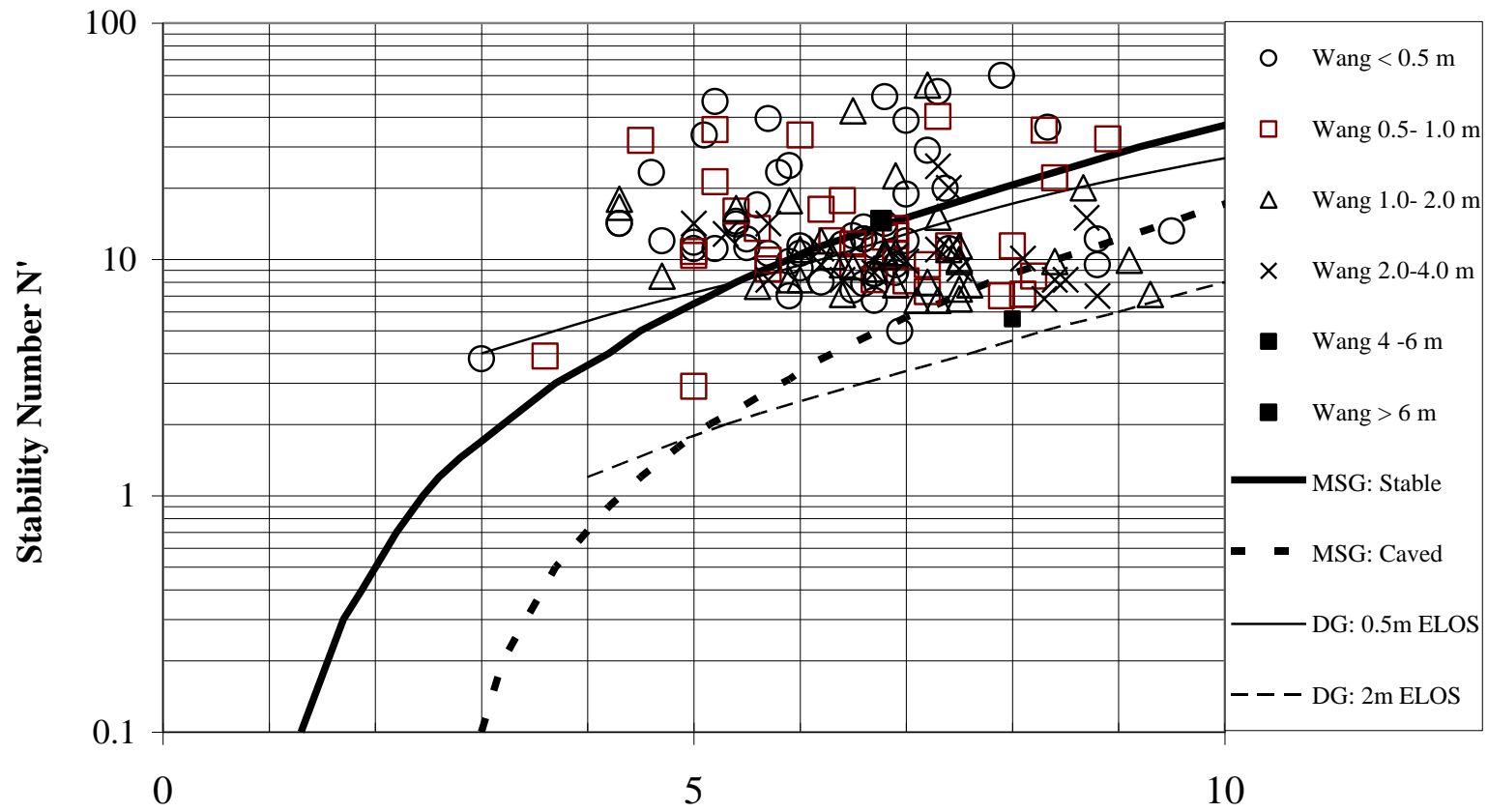

Hydraulic Radius (m)

Figure 6 Flin Flon, Canada area data from Wang (2004): 148 cases

\section{Analysis}

Before logistic regression was used to model new design lines, the first step was to plot the collected data against the original MSG and DG lines. The Wang (2004) database is outside the zone of interest for the study. However, to create an interesting discussion on the modelling of stability design lines with additional data, an analysis was conducted without (257 cases) and with (405 cases) the Wang (2004) data. Tables 1 and 2 describe the percentage of points from each ELOS category plotting in the defined stability zones. 
Figures 7 and 8 show the compiled databases and existing design lines. Note that the ELOS $1 \mathrm{~m}$ line has been omitted for ease of comparison.

The number of points from each ELOS category were compared to the stable, transition, and caved zones of the MSG. The points were also classified based on the ELOS $<0.5 \mathrm{~m}, 0.5-2 \mathrm{~m}$ transition zone, ELOS $>2 \mathrm{~m}$ zones, and undefined in areas where the DG lines are truncated. For the dataset composed of 257 cases, the key observation from the graphs and tables is that no point with ELOS $>1 \mathrm{~m}$ plots in the stable zone and above the ELOS $<0.5 \mathrm{~m}$ line. In addition, $80-90 \%$ of ELOS $>2 \mathrm{~m}$ data points respectively plot in the caved zone and below the ELOS $>2 \mathrm{~m}$ line. However, some ELOS data points have a lower value than the zone in which they plot. Similar results occur when the Wang (2004) data is included except for the plotting of some points with ELOS $>2 \mathrm{~m}$ in the previously suggested stable and ELOS $<0.5 \mathrm{~m}$ zones.

It was an interesting exercise to classify the data in relation to the DG and MSG lines. The data can be simply used to estimate quantitative values for the MSG stability lines. However, an extended set of ELOS design lines was desired. Mawdesley and Trueman (2003) demonstrated the use of logistic regression to create isoprobability contours defining the predicted probability of an event occurrence for a stability class, as the stability boundaries in their dataset did not clearly separate stable and unstable cases. Logistic regression methodology was used to model design lines for the cases of ELOS $<0.5,<1,<2$ and $<4$ for different combinations of data. A new set of ELOS lines can be modelled for any level of probability. For the purpose of the paper, the probability of a data point being less than each ELOS interval was assigned $80 \%$. In other words, a particular ELOS line would theoretically represent the location where the odds of being $<$ ELOS line value to being >ELOS line value are 4:1. The model is based on the collected data and the local external factors which created stability or instability. Depending on the database chosen and the desired probability of prediction, many different positions of design lines can be modelled. The modelled $\mathrm{P}=0.8$ design lines are shown for the 257 case dataset (Figure 9) and 405 case dataset (Figure 10). The data points with $>2$ m ELOS in the Wang (2004) database are partially responsible for the more conservative ELOS $<0.5$ and $<1$ design lines in Figure 10. If the probability of having correct prediction is not important then a more aggressive set of design lines such as $\mathrm{P}=0.5$ may be modelled. Alternatively, a set of lines based on $\mathrm{P}=0.99$ could be used if correct prediction was mandatory. However, the probability calculation only fits the logistic regression function to the data and may not represent the actual percentage of correctly classified cases. An analysis of correctly classified cases for different levels of probability is required. From the classification analysis, different sets of modelled probability lines can be chosen based on percentage of correct prediction. For the 257 case dataset, the probability lines which represent the highest number of correct predictions above and below each ELOS line are shown in Figure 11. These lines represent a division where the largest number of correct classifications occurs for each category of data for a specific ELOS line. For example, in consideration of the ELOS $<4$ line, the $\mathrm{P}=0.86$ logistic regression line results in 28 of the 35 cases with ELOS $>4$ plotting below the ELOS $<4$ line and 172 of the 222 cases with ELOS $<4$ plotting above the line. This results in a maximised $80 \%$ and $77 \%$ correct classification respectively. The other lines show comparable classification. Detailed classification analysis will be presented in the thesis.

Table 1 Number of ELOS cases in each Stability Zone for 257 cases

\begin{tabular}{|c|c|c|c|c|c|c|c|c|c|c|}
\hline ELOS & \multicolumn{2}{|c|}{$0.0-0.5 \mathrm{~m}$} & \multicolumn{2}{|c|}{$>0.5-1.0 \mathrm{~m}$} & \multicolumn{2}{|c|}{$>1-2.0 \mathrm{~m}$} & \multicolumn{2}{|c|}{$>2.0-4.0 \mathrm{~m}$} & \multicolumn{2}{|c|}{$>4 \mathrm{~m}$} \\
\hline Stability & Cases & & Cases & & Cases & & Cases & & Case & \\
\hline Zone & 108 & $\%$ & 39 & $\%$ & 39 & $\%$ & 36 & $\%$ & 35 & $\%$ \\
\hline ELOS $<0.5$ & 35 & 32 & 2 & 5 & 0 & 0 & 0 & 0 & 0 & 0 \\
\hline Transition & 52 & 48 & 20 & 51 & 9 & 23 & 4 & 11 & 1 & 3 \\
\hline ELOS $>2$ & 13 & 12 & 8 & 21 & 26 & 67 & 29 & 81 & 33 & 94 \\
\hline Undefined & 8 & 7 & 9 & 23 & 4 & 10 & 3 & 8 & 1 & 3 \\
\hline MSG upper & 37 & 34 & 5 & 13 & 0 & 0 & 0 & 0 & 0 & 0 \\
\hline Transition & 56 & 52 & 22 & 56 & 6 & 15 & 3 & 8 & 1 & 3 \\
\hline MSG lower & 15 & 14 & 12 & 31 & 33 & 85 & 33 & 92 & 34 & 97 \\
\hline
\end{tabular}


Table 2 Number of ELOS cases in each Stability Zone for 405 cases

\begin{tabular}{|c|c|c|c|c|c|c|c|c|c|c|}
\hline ELOS & \multicolumn{2}{|c|}{$0.0-0.5 \mathrm{~m}$} & \multicolumn{2}{|c|}{$>0.5-1.0 \mathrm{~m}$} & \multicolumn{2}{|c|}{$>1.0-2.0 \mathrm{~m}$} & \multicolumn{2}{|c|}{$>2.0-4.0 \mathrm{~m}$} & \multicolumn{2}{|c|}{$>4 \mathrm{~m}$} \\
\hline Stability & Cases & & Cases & & Cases & & Cases & & Case & \\
\hline Zone & 161 & $\%$ & 74 & $\%$ & 76 & $\%$ & 57 & $\%$ & 37 & $\%$ \\
\hline ELOS $<0.5$ & 65 & 40 & 23 & 31 & 11 & 14 & 6 & 11 & 0 & 0 \\
\hline Transition & 75 & 47 & 35 & 47 & 40 & 53 & 19 & 33 & 3 & 8 \\
\hline ELOS $>2$ & 12 & 7 & 7 & 9 & 21 & 28 & 32 & 56 & 33 & 89 \\
\hline Undefined & 9 & 6 & 9 & 12 & 4 & 5 & 0 & 0 & 1 & 3 \\
\hline Stable & 62 & 39 & 22 & 30 & 10 & 13 & 5 & 9 & 0 & 0 \\
\hline Transition & 81 & 50 & 39 & 53 & 32 & 42 & 12 & 21 & 2 & 5 \\
\hline Caved & 18 & 11 & 13 & 18 & 34 & 45 & 40 & 70 & 35 & 89 \\
\hline
\end{tabular}

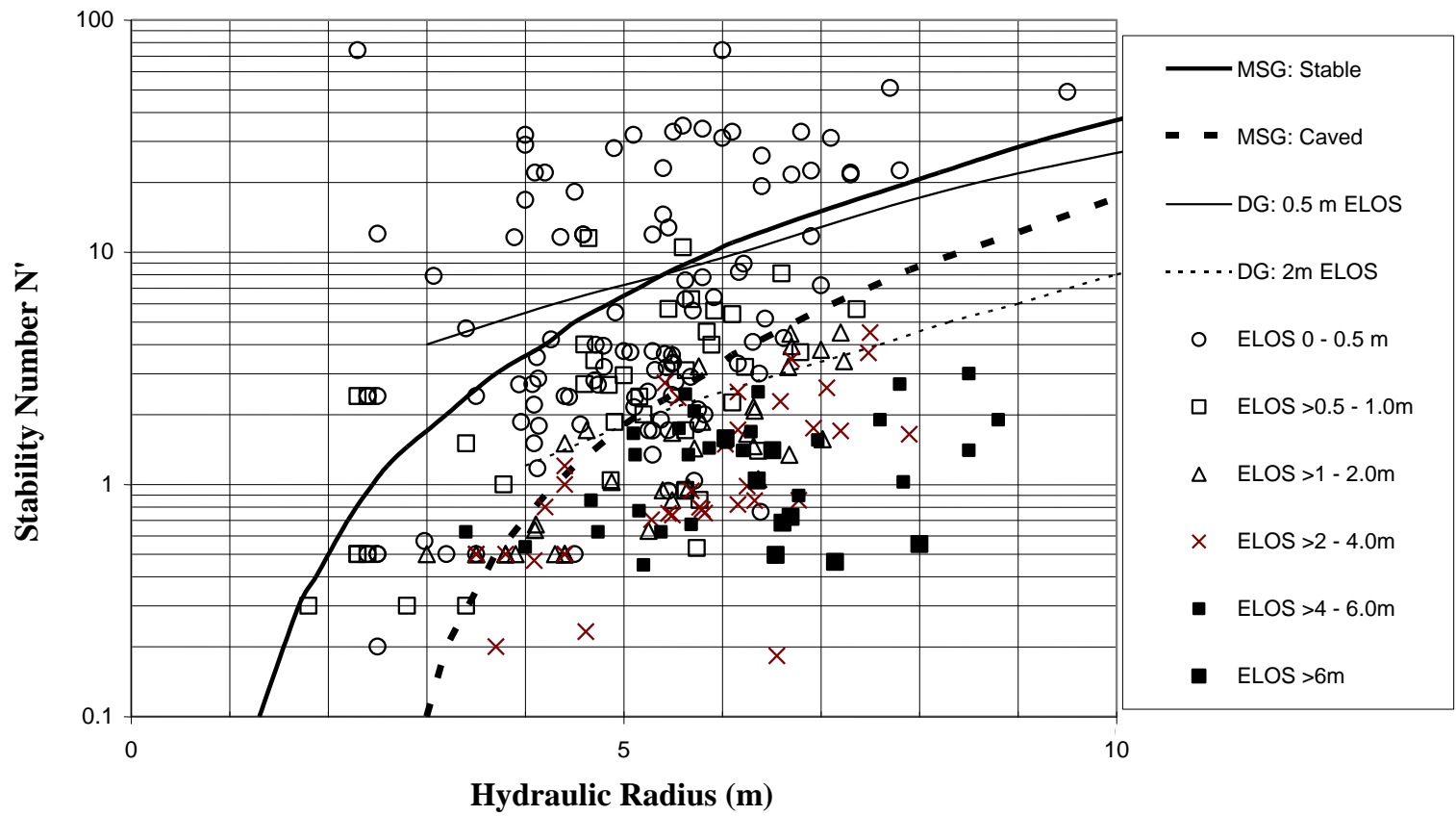

Figure 7 Data plotted with modified stability graph and DG lines (257 cases) 


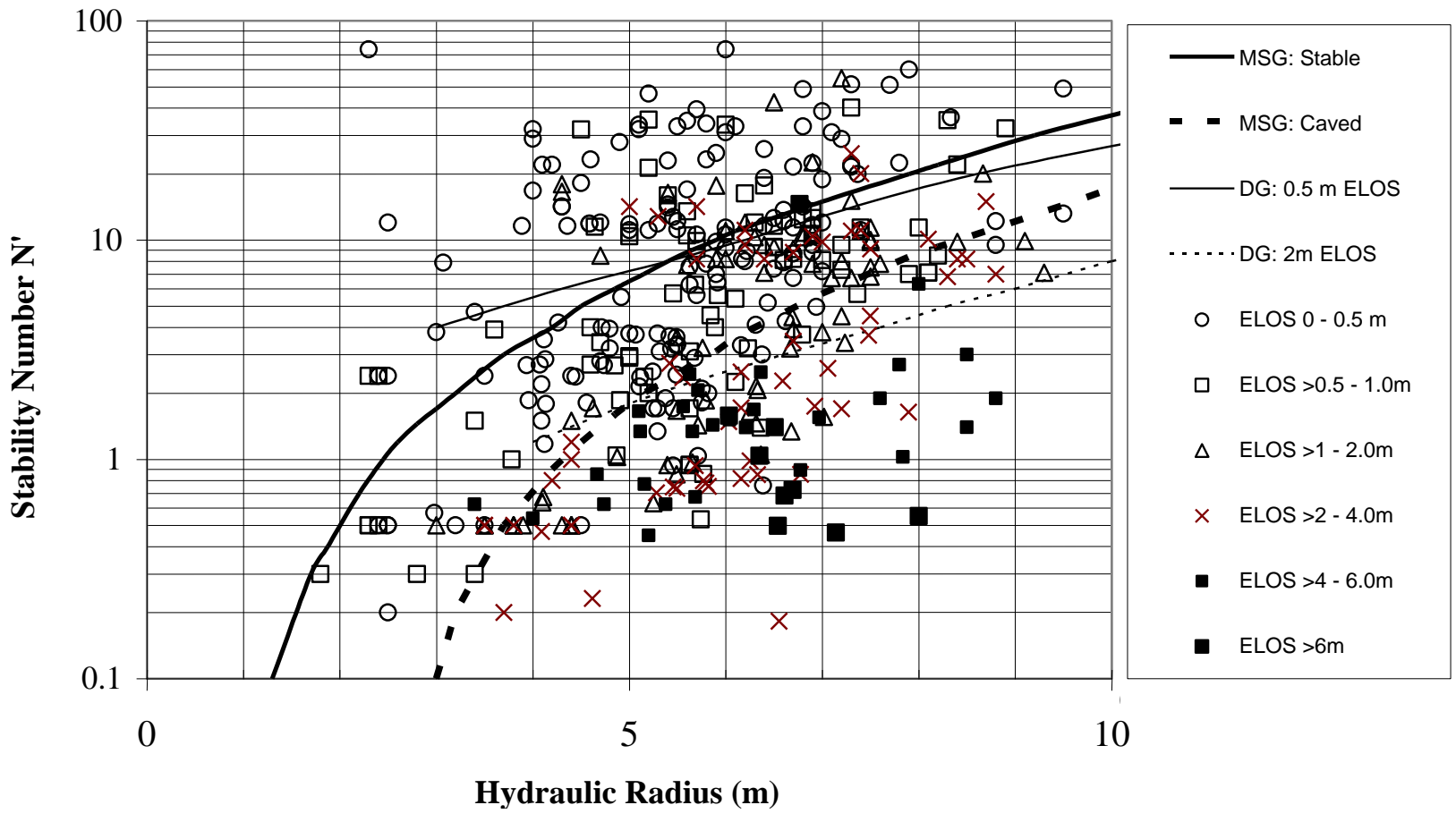

Figure 8 Data plotted with modified stability graph and DG lines (405 cases)

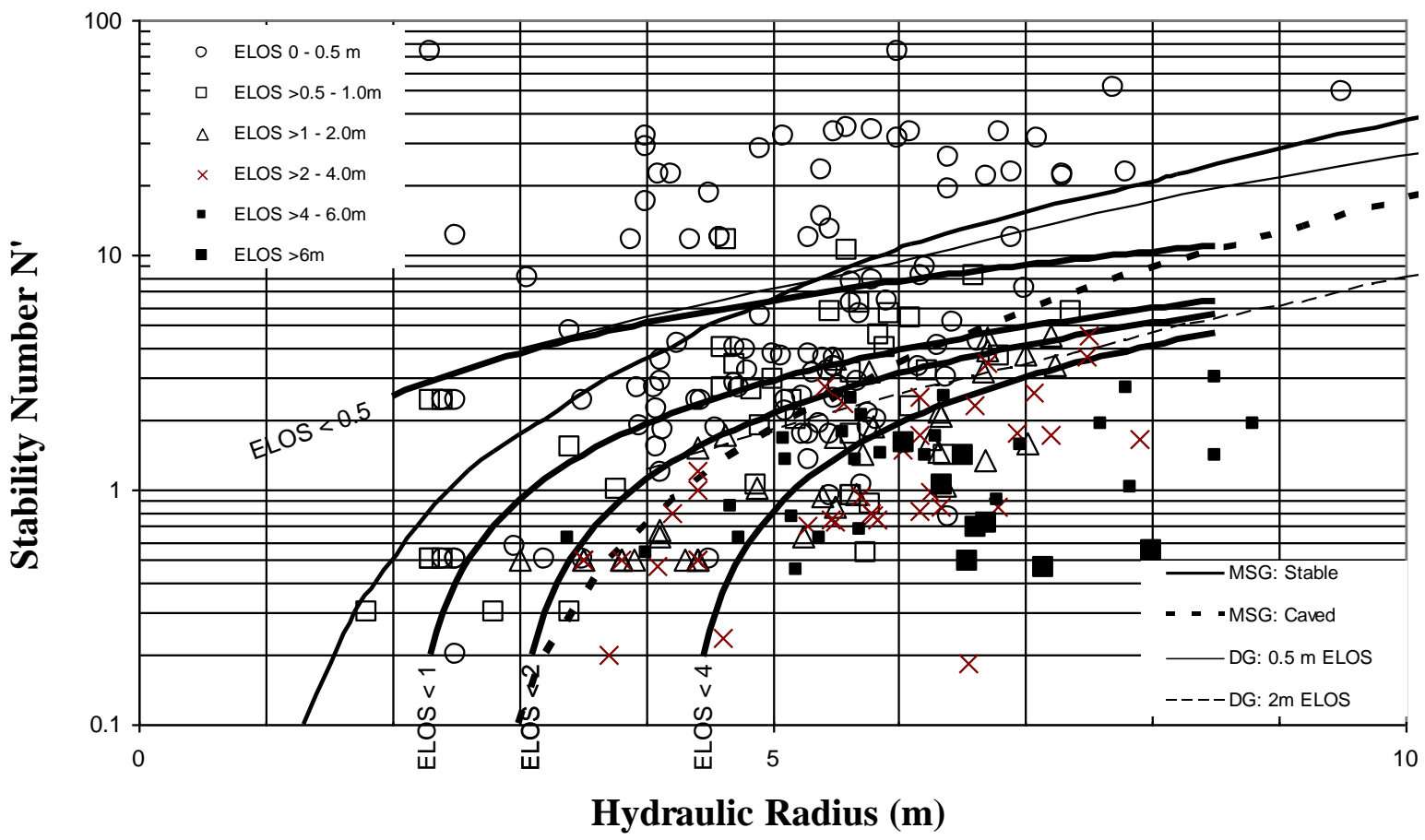

Figure 9 Use of logistic regression to define $P=0.8$ design lines for 257 case database 


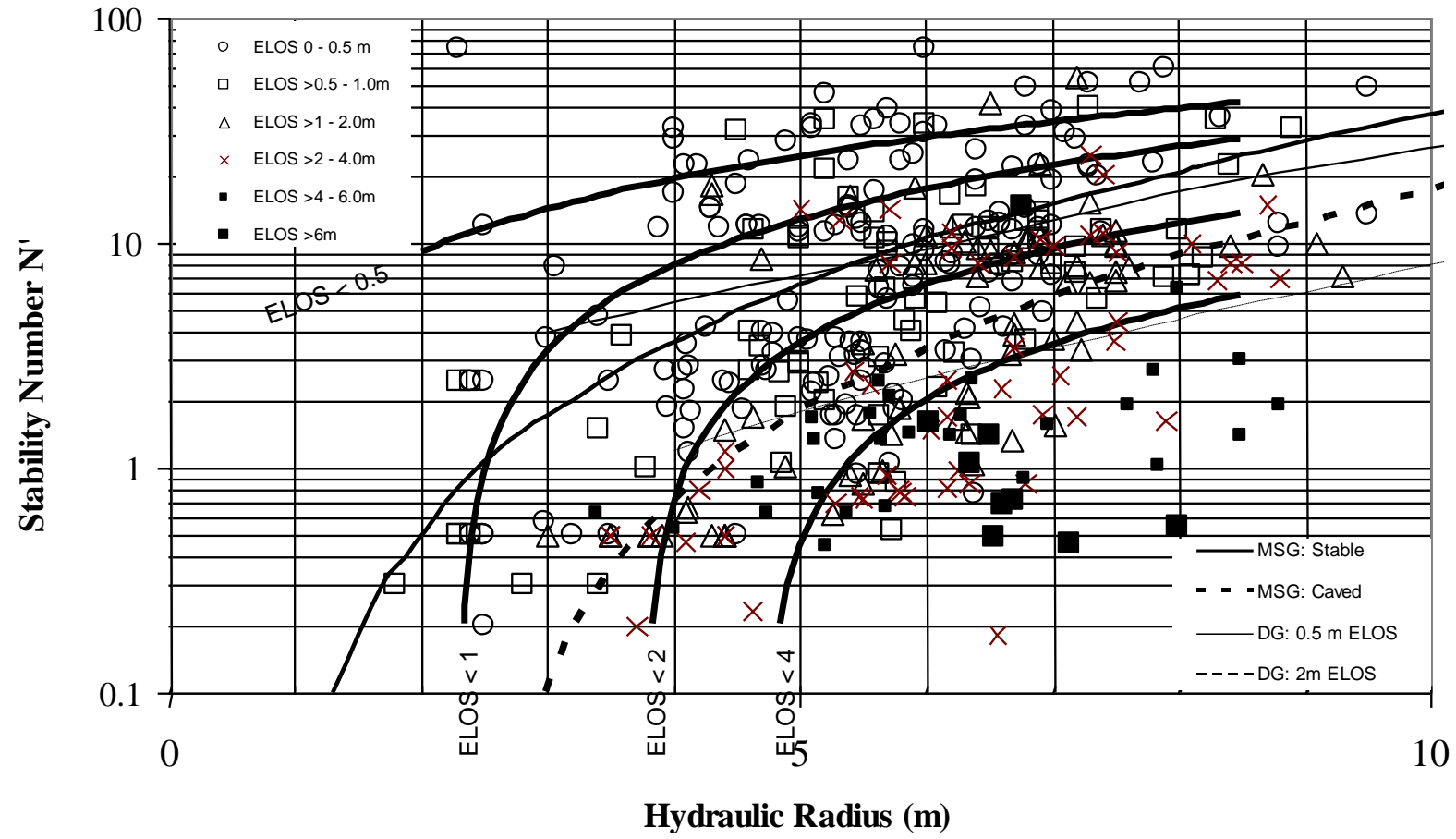

Figure 10 Use of logistic regression to define $P=0.8$ design lines for 405 case database
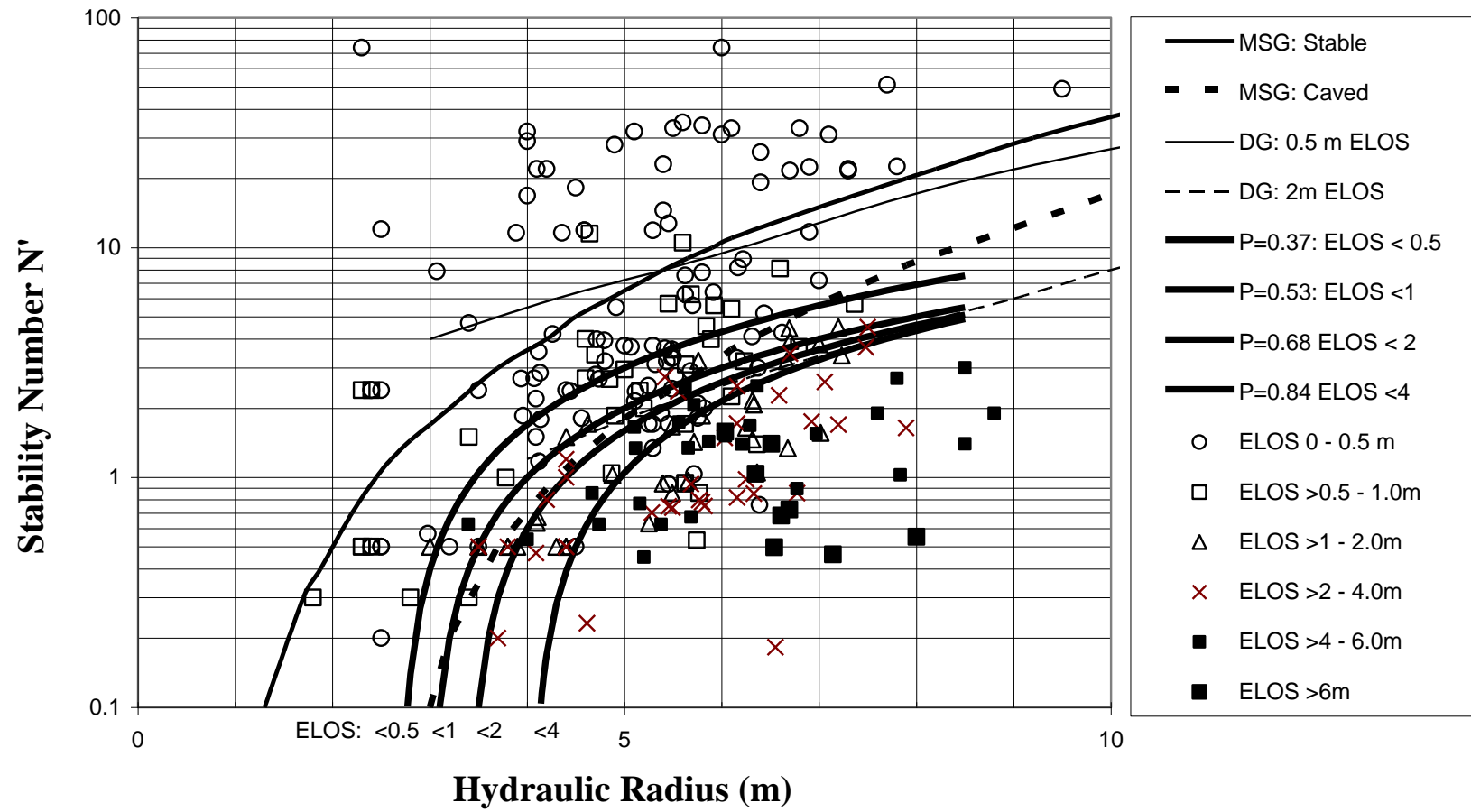

Hydraulic Radius (m)

Figure 11 Use of classification analysis to define logistic regression lines for 257 cases

\section{$5 \quad$ Limitations of the design approach}

Factors limiting the accuracy and application of the empirical DG design method come from two general categories:

1. Challenges for quantifying strength properties for a rock mass (rock mass conditions).

2. Difficulty assessing the influence of the many varied factors influencing ore extraction (mining factors). 
These two general categories influencing HW dilution are explained in more detail.

\subsection{Rock mass conditions}

A major source of uncertainty in estimating dilution is in quantifying rock mass properties based on the Q' classification system. Milne et al. (1992) present a review of the variability in N' based on challenges in determining Q'. Based on the reported subjectivity in estimating Q' and, using the DG presented in this paper, a $2.0 \mathrm{~m}$ range in dilution values could easily be predicted. Techniques exist for reducing the subjectivity in estimating Q'. However, these methods are seldom applied in a mining environment (Milne et al., 1998).

There are other significant problems associated with obtaining representative rock classification values which include the following:

- Limited HW exposure.

- Difficulty interpreting core data.

- Variable HW rock quality.

- Multiple zones of HW rock (layered).

- Difficulty interpreting discrete features, such as shears and dykes.

\subsection{Mining factors}

There are many mining controlled practices that will act to increase or decrease dilution. One mine's standard mining procedure could easily produce less dilution than another mine's practice. It is very difficult to include these mining influences on predicted HW dilution, though several authors have tried to quantify some of these factors (Wang, 2004). A partial list of these factors is given:

- Blast damage. A mine's blasting practice can significantly increase or decrease actual dilution relative to predicted dilution.

- Complex hanging wall geometries. Attempting to create complex HW geometries by following a complex ore grade limit can significantly increase dilution. Quantifying this influence is difficult.

- Undercutting and overcutting the hanging wall can lead to increased dilution.

- Cable bolt support is often used to try to control dilution. The effect of different degrees of cable support and cable installation cannot easily be assessed.

- Delayed mucking and exposure time are recognised factors influencing dilution.

Some other limitations to the method more specific to the collected databases are as follows:

- Data collection was focussed on stope HW stability and only considered HR<10.

- Error associated with the requirement of averaging the HW rock mass quality as a single input into the empirical design methods.

- Effect of the external factors such as stress, undercutting, faulting, etc. are not directly accounted for, though a high probability stability design line may eliminate the worst effect of the factors.

- Numerical modelling should be used for mine-wide sequencing/stability in conjunction with the consideration of the DG lines for individual stope HW performance as the methods do not consider stability of secondary crosscuts and pillars.

- Incomplete recovery of stope toes or ore left as a skin on the HW, resulting in increased stability.

- Mining out of sequence, triple lift pendants, poor cement fill quality or lack of tight fill and/or delayed fill in primary stopes may lead to greater failure than predicted. 
The data bases presented in this paper represent different mining practices as well as different availability of rock mass classification data. The variability in the design lines reflects this. Like any design method, empirical methods are useful tools for prediction when used for conditions similar to those which existed for the development of the design method. The presentation of different HW dilution data bases gives the engineer the option of choosing the data base that most closely represents conditions at the mine

\section{Summary}

With much support from industry, experience was gained in the application of the described empirical methods over a period of four years through discussions at industry short courses, site visits, consultants' visits, employment, and data collection at underground mines in Canada, Australia, and Kazakhstan. This included the compilation of 405 cases, of which 171 were collected from mine sites along with 234 cases from literature. The data was collected in areas of the DG which previously lacked data. During data collection, insight was gained into the effect of factors not included as inputs in the design method.

Some of the databases referenced in this paper have considered, or attempted site specific correction factors and are recommended for referral. The new database represents a wide range of effect of these factors. A set of design lines was created as an example of the use of logistic regression.

The cost of increased dilution balanced against the cost (and time) required to reduce dilution by factors such as decreasing stope size, increasing HW support or the use of controlled blasting techniques will influence the appropriate probability lines to use for dilution prediction.

A supplementary database was discussed to show the effects of additional data on the creation of design lines using the statistical approach. The DG method has been found to be very useful when used within its limitations and in conjunction with other tools for mine design.

\section{Acknowledgements}

The initial support for this research project by Hudson Bay Mining and Smelting, (Canada), Cameco, (Canada) and the Natural Sciences and Engineering Research Council of Canada is greatly appreciated. Special thanks to HBMS: Brent Christensen, Ken Pawliuk; Cameco: Dave Neuberger; Xstrata Zinc: Leigh Neindorf, Don Grant, and Jeremy Doolan; and Denis Usmanov for his aid as a translator through Kazakhstan.

\section{References}

Barton, N., Lien, R. and Lunde, J. (1974) Engineering classifications of rock masses for the design of tunnel support. Rock Mech., Vol. 6, pp. 97-106.

Bienawski, Z.T. (1976) Rock Mass Classification in Rock Engineering. Proceedings of the Symposium on Exploration for Rock Engineering, Johannesburg, South Africa, pp. 97-106.

Brady, T., Pakalnis, R. and Clark, L. (2005) Design in Weak Rock Masses, Nevada Underground Mining Operations, SME-AGM, Salt Lake City, 9 p.

Capes, G.W., Milne, D.M. and Grant, D.R. (2005) Stope hangingwall design approaches at the Xstrata Zinc, George Fisher Mine, North Queensland, Australia. Proceedings ARMA Alaska Rocks 2005: Rock Mechanics for Energy, Mineral, and Infrastructure Development in the Northern Regions, University of Alaska-Anchorage, USA, June.

Capes, G.W., Doolan, J.P. and Neindorf, L. (2007) Stope design considerations using rock mass classification tools at the Xstrata Zinc George Fisher mine. Proceedings of the International Workshop on Rock Mass Classification in Underground Mining, NIOSH, Information Circular 9498, May.

Clark, L. and Pakalnis, R. (1997) An empirical design approach for estimating unplanned dilution from open stope hangingwalls and footwalls. 99th Annual AGM-CIM conference, Vancouver, BC.

Clark, L. (1998) Minimizing dilution in open stope mining with a focus on stope design and narrow vein longhole blasting, Msc Thesis, University of British Columbia, Canada, 316 p.

Dishaw, G.R. (2005) Rabbit Lake Operation: Canada's Longest Operating Uranium Mine - 30 Years and Still Glowing. CIM-AGM, Toronto, Canada.

Forster, K., Milne, D. and Pop, A. (2007) Mining and Rock Mass Factors Influencing Hanging Wall Dilution, 1st Annual Canada-US Rock Mechanics Symposium, Vancouver, Canada, May 2007. 
Grenfell, K. and Haydon, M. (2006) Challenges in modelling large complex orebodies at the George Fisher north mine. Proceedings Sixth International Mining Geology Conference (Darwin, Northern Territory, Australia, 21-23 August).

Mathews, K.E., Hoek, E., Wyllie, D. and Stewart, S.B. (1981) Prediction of stable excavation spans for mining below 1000 metres in hard rock, Canada: CANMET, Dept. of Energy, Mines and Resources, DSS Serial No. OSQ8000081, DSS File No. 17SQ.23440-0-9020.

Mawdesley, C. and Trueman, R. (2003) Predicting open stope stability and cavability using the Extended Mathews stability graph, 1st AGCM Conference, Ground Control in Mining - Technology and Practice, November.

Miller, F., Jacobs, D. and Potvin, Y. (1992) Laser measurement of open stope dilution. CIM Bulletin, Vol. 85, July August.

Milne, D., Germain, P. and Potvin, Y. (1992) Measurement of Rock Mass Properties for Mine Design. Proceedings ISRM-Eurock Symposium on Rock Characterization, Chester, England, pp. 245-250.

Milne, D., Hadjigeorgiou, J. and Pakalnis, R. (1998) Rock mass characterization for underground hard rock mines. Tunnelling Underground Space Technology, Vol. 13(4), pp. 383-391.

Pakalnis, R. and Vongpaisal, S. (1998) Empirical design methods-UBC geomechanics. Proc. Can. Inst. Min., AGM, Montreal.

Potvin, Y. (1988) Empirical open stope design in Canada, Ph.D. thesis. The University of British Columbia, 350 p.

Sutton, D. (1998) Use of the Modified Stability Graph to Predict Stope Instability and Dilution at Rabbit Lake Mine, Saskatchewan, University of Saskatchewan Design Project, Canada.

Syme, E.C. and Bailes, A.H. (1993) Stratigraphic and tectonic settings of early proterozoic volcanogenic massive sulphide deposits, Flin Flon, Manitoba. Economic Geology, Vol. 88.

Wang, J. (2004) Influence of stress, undercutting, blasting, and time on open stope stability and dilution. PhD Thesis, University of Saskatchewan.

Wang, J., Milne, D., Wegner, L. and Reeves, M. (2006) Numerical evaluation of the effects of stress and excavation surface geometry on the zone of relaxation around open stope hanging walls. International Journal of Rock Mechanics and Mining Sciences, 44 (February), pp. 289-298. 